Pacific Journal of Mathematic 


\section{A MULTIPLE SERIES TRANSFORMATION OF THE VERY WELL POISED ${ }_{2 k+4} \Psi_{2 k+4}$}

\section{Stephen C. Milne}

A multiple series generalization of the $q$-analog of Whipple's theorem is derived for ${ }_{2 k+4} \Psi_{2 k+4}$ by applying recent analytical techniques of Askey and Ismail to Andrews' multiple series transformation of a well poised ${ }_{2 k+4} \Phi_{2 k+3}$.

1. Introduction. The bilateral basic hypergeometric function is

$$
{ }_{m} \Psi_{n}\left[\begin{array}{l}
a_{1}, a_{2}, \cdots, a_{m} ; q, t \\
b_{1}, b_{2}, \cdots, b_{n}
\end{array}\right]=\sum_{j=-\infty}^{\infty} \frac{\left(a_{1}\right)_{j}\left(a_{2}\right)_{j} \cdots\left(a_{m}\right)_{j} t^{j}}{\left(b_{1}\right)_{j}\left(b_{2}\right)_{j} \cdots\left(b_{n}\right)_{j}}
$$

where

$$
(a ; q)_{\infty}=\prod_{n=0}^{\infty}\left(1-a q^{n}\right), \quad|q|<1
$$

and

$$
(a)_{j}=(a ; q)_{j}=(a)_{\infty}\left(a q^{j}\right)_{\infty}^{-1}
$$

or

$$
(a)_{-n}=\left(1-\frac{a}{q^{n}}\right)^{-1} \cdots\left(1-\frac{a}{q}\right)^{-1}=(-a)^{-n} q^{n(n+1) / 2}(q / a)_{n}^{-1}
$$

Thus

$$
\begin{aligned}
& { }_{m} \Psi_{n}\left[\begin{array}{c}
a_{1}, \cdots, a_{m} ; q, t \\
b_{1}, \cdots, b_{n}
\end{array}\right] \\
& \begin{aligned}
(1.4)= & \sum_{j=0}^{\infty} \frac{\left(a_{1}\right)_{j} \cdots\left(a_{m}\right)_{j} t^{j}}{\left(b_{1}\right)_{j} \cdots\left(b_{n}\right)_{j}}+\sum_{j=1}^{\infty} \frac{\left(\frac{q}{b_{1}}\right)_{j} \cdots\left(\frac{q}{b_{n}}\right)_{j}}{\left(\frac{q}{a_{1}}\right)_{j} \cdots\left(\frac{q}{a_{m}}\right)_{j}}\left(\frac{b_{1} \cdots b_{n}}{a_{1} \cdots a_{m} t}\right)^{j}(-1)^{j(m-n)} \\
& \times q^{j(j+1)(m-n) / 2} .
\end{aligned}
\end{aligned}
$$

Hence we see that to insure convergence we must require $n \leqq m$. Also $b_{h} \neq q^{-N}, a_{h} \neq q^{N+1}$ for any nonnegative integer $N$. Finally if $n<m$, we need only in addition require $|t|<1$; however, if $n=m$, we need also

$$
\left|\frac{b_{1} \cdots b_{n}}{a_{1} \cdots a_{m}}\right|<|t|<1 .
$$


Bailey's sum of the very well poised ${ }_{6} \Psi_{6}$ is

$$
\begin{aligned}
& { }_{6} \Psi_{6}\left[\begin{array}{c}
q \sqrt{a},-q \sqrt{a}, b, c, d, e \\
\sqrt{a},-\sqrt{a}, \frac{a q}{b}, \frac{a q}{c}, \frac{a q}{d}, \frac{a q}{e} ; q, \frac{a^{2} q}{b c d e}
\end{array}\right] \\
& =\Pi\left[\begin{array}{c}
a q, \frac{a q}{b c}, \frac{a q}{b d}, \frac{a q}{b e}, \frac{a q}{c d}, \frac{a q}{c e}, \frac{a q}{d e}, q, \frac{q}{a} \\
\frac{q}{b}, \frac{q}{c}, \frac{q}{d}, \frac{q}{e}, \frac{a q}{b}, \frac{a q}{c}, \frac{a q}{d}, \frac{a q}{e}, \frac{a^{2} q}{b c d e}
\end{array}\right]
\end{aligned}
$$

where

$$
\Pi\left[\begin{array}{c}
\alpha_{1}, \cdots, \alpha_{r} \\
\beta_{1}, \cdots, \beta_{s}
\end{array}\right]=\frac{\left(\alpha_{1}\right)_{\infty} \cdots\left(\alpha_{r}\right)_{\infty}}{\left(\alpha_{1}\right)_{\infty} \cdots\left(\alpha_{s}\right)_{\infty}}
$$

The identity (1.5) is probably the most general summation identity known for bilateral basic hypergeometric series. Andrews [1, §3] deduces many important diverse results in number theory from (1.5). Other $q$-series identities that follow from the ${ }_{6} \Psi_{6}$ summation are given by Slater [11].

There are five known proofs of (1.5). Bailey's original proof $[6, \S 4]$ relies on ingenious combinations of various transformation formulas he had developed for ordinary and basic hypergeometric series. Slater [12] uses an analog of the Barnes-type integral, Lakin [12] combines a $q$-difference equation technique with Carlson's theorem on entire functions, and Andrews [1, §3] provides a more elementary proof which utilizes $q$-difference equations together with the uniqueness of a Laurent series expansion about the origin. In obtaining (1.5) directly from the ${ }_{6} \Phi_{5}$ summation formula, Askey and Ismail [5] have recently given the most elementary proof of all.

The ${ }_{6} \Phi_{5}$ summation formula is:

$$
\begin{array}{r}
{ }_{6} \Phi_{5}\left[\begin{array}{l}
a, q \sqrt{a},-q \sqrt{a}, b, c, d \\
\sqrt{a},-\sqrt{a}, \frac{a q}{b}, \frac{a q}{c}, \frac{a q}{d} ; q, \frac{a q}{b c d}
\end{array}\right] \\
\quad=\Pi\left[\begin{array}{l}
a q, \frac{a q}{b c}, \frac{a q}{b d}, \frac{a q}{c d} \\
\frac{a q}{b}, \frac{a q}{c}, \frac{a q}{d}, \frac{a q}{b c d}
\end{array}\right]
\end{array}
$$

where

$$
{ }_{m} \Phi_{n}\left[\begin{array}{l}
a_{1}, \cdots, a_{m} \\
b_{1}, \cdots, b_{n}
\end{array} ; q, t\right]=\sum_{j=0}^{\infty} \frac{\left(a_{1}\right)_{j}\left(a_{2}\right)_{j} \cdots\left(a_{m}\right)_{j} t^{j}}{\left(b_{1}\right)_{j}\left(b_{2}\right)_{j} \cdots\left(b_{n}\right)_{j}(q)_{j}}
$$


To the end of proving ${ }_{6} \Psi_{6}$ Askey and Ismail first make the key observation that both sides of (1.5) are analytic functions of $z=a / e$ is a disk of positive radius about the origin. They then show that the ${ }_{6} \Phi_{5}$ summation formula in (1.6) is equivalent to the statement that these two analytic functions agree when $z=q^{m}, m=0,1,2, \cdots$. Thus they must be identically equal since 0 is an interior point of the domain of analyticity. The identity in (1.5) follows.

This proof is motivated by the fact that when $e=q$ the series (1.5) becomes the series in (1.6) since $1 /(q ; q)_{n}=0$ when $n=-1$, $-2, \ldots$ Ismail [8] has used the above analytical method to extend another result for a power series to a Laurent series.

In this paper we make use of Askey and Ismail's proof of (1.5) and Andrews' [2] transformation of a terminating well poised ${ }_{2 k+4} \Phi_{2 k+3}$ to prove:

THEOREM 1.7.

${ }_{2 k+4} \Psi_{2 k+4}$

$\times\left[\begin{array}{l}q \sqrt{a},-q \sqrt{a}, b_{1}, c_{1}, \cdots, b_{k-1}, c_{k-1}, b_{k}, c_{k}, e, f \\ \sqrt{a},-\sqrt{a}, \frac{a q}{b_{1}}, \frac{a q}{c_{1}}, \ldots, \frac{a q}{b_{k-1}}, \frac{a q}{c_{k-1}}, \frac{a q}{b_{k}}, \frac{a q}{c_{k}}, \frac{a q}{e}, \frac{a q}{f} ; q, \frac{a^{k+1} q^{k}}{b_{1} \cdots b_{k} c_{1} \cdots c_{k} e f}\end{array}\right]$

$$
=\Pi\left[\begin{array}{l}
a q, \frac{a q}{b_{k} c_{k}}, \frac{a q}{b_{k} e}, \frac{a q}{b_{k} f}, \frac{a q}{c_{k} e}, \frac{a q}{c_{k} f}, \frac{a q}{e f}, q, \frac{q}{a} \\
\frac{q}{b_{k}}, \frac{q}{c_{k}}, \frac{q}{e}, \frac{q}{f}, \frac{a q}{b_{k}}, \frac{a q}{c_{k}}, \frac{a q}{e}, \frac{a q}{f}, \frac{a^{2} q}{b_{k} c_{k} e f}
\end{array}\right]
$$

$$
\begin{aligned}
& \times \Pi\left[\begin{array}{l}
\frac{b_{1}}{a}, \cdots, \frac{b_{k-1}}{a} \\
\frac{b_{1}}{f}, \cdots, \frac{b_{k-1}}{f}
\end{array}\right] \times \Pi\left[\begin{array}{c}
b_{1}, \cdots, b_{k-1} \\
\frac{f b_{1}}{a}, \cdots, \frac{f b_{k-1}}{a}
\end{array}\right] \\
& \times \Pi\left[\begin{array}{l}
\frac{q f}{c_{1}}, \cdots, \frac{q f}{c_{k-1}} \\
\frac{a q}{c_{1}}, \cdots, \frac{a q}{c_{k-1}}
\end{array}\right] \times \Pi\left[\begin{array}{l}
\frac{q a}{f c_{1}}, \cdots, \frac{q a}{f c_{k-1}} \\
\frac{q}{c_{1}}, \cdots, \frac{q}{c_{k-1}}
\end{array}\right] \\
& \text { (1.11) } \quad \times \sum_{m_{1}, \ldots, m_{k-1} \geqq 0} \frac{\left(q a / b_{1} c_{1}\right)_{m_{1}}\left(\alpha q / b_{2} c_{2}\right)_{m_{2}} \cdots\left(a q / b_{k-1} c_{k-1}\right)_{m_{k-1}}}{(q)_{m_{1}}(q)_{m_{2}} \cdots(q)_{m_{k-1}}} \\
& \times \frac{\left(b_{2} f / a\right)_{m_{1}}\left(c_{2} f / a\right)_{m_{1}}\left(b_{3} f / a\right)_{m_{1}+m_{2}}\left(c_{3} f / a\right)_{m_{1}+m_{2}}}{\left(q f / b_{1}\right)_{m_{1}}\left(q f / c_{1}\right)_{m_{1}}\left(q f / b_{2}\right)_{m_{1}+m_{2}}\left(q f / c_{2}\right)_{m_{1}+m_{2}}} \cdots \\
& \times \frac{\left(b_{k} f / a\right)_{m_{1}+\cdots+m_{k-1}} \cdot\left(c_{k} f / a\right)_{m_{1}+\cdots+m_{k-1}} \cdot(e f / a)_{m_{1}+\cdots+m_{k-1}}}{\left(q f / b_{k-1}\right)_{m_{1}+\cdots+m_{k-1}} \cdot\left(q f / c_{k-1}\right)_{m_{1}+\cdots+m_{k-1}} \cdot\left(b_{k} c_{k} e f / a^{2}\right)_{m_{1}+\cdots+m_{k-1}}} \\
& \times\left(\frac{a q}{b_{2} c_{2}}\right)^{m_{1}}\left(\frac{a q}{b_{3} c_{3}}\right)^{m_{1}+m_{2}} \cdots\left(\frac{a q}{b_{k-1} c_{k-1}}\right)^{m_{1}+m_{2}+\cdots+m_{k-2}} \cdot q^{m_{1}+\cdots+m_{k-1}},
\end{aligned}
$$


where

$$
\left(\frac{a q}{b_{i} c_{i}}\right)=q^{-N_{i}}
$$

$1 \leqq i \leqq k-1, N_{i}$ a fixed positive integer.

Note that for $k=1$, Theorem 1.7 reduces to Bailey's sum of the very well poised ${ }_{6} \Psi_{6}$ given in (1.5).

The condition given by (1.12) for the parameters $b_{i}$ and $c_{i}$ only applies when $k \geqq 2$. In these cases the series on the left hand side of (1.8) does not terminate while the series on the right hand side in (1.11) does. When the series in (1.11) does not terminate there are additional terms on the right hand side. For $k=2 \mathrm{M}$. Jackson [9] has proven the nonterminating form of Theorem 1.7.

Andrews $[1, \S 3]$ has introduced the Laurent series $K_{\lambda, k, i}\left(a_{0}, \ldots, a_{\lambda}\right.$; $z ; q)=K_{\lambda, k, i}((a) ; z ; q)$ which generalizes bilateral basic hypergeometric series. As summarized in [4, chapter 7] the function $K_{\lambda, k, i}((a) ; z ; q)$ plays a key role in the proof of numerous partition identities of Rogers-Ramanujan type.

It turns out that the sum on the left hand side of (1.8) is $K_{2 k+1, k, 1}((a) ; z ; q)$. This suggests it may be possible to discover a multiple series transformation for $K_{\lambda, k, i}((a) ; z ; q)$ that is similar to Theorem 1.7. Furthermore, $K_{\lambda, k, i}((a) ; z ; q)$ should be regarded as a function of $z / a_{\lambda}$ rather than $z$.

2. Proof of Theorem 1.7. In order to prove Theorem 1.7 we need the following result of Andrews [2, §2] which generalizes the terminating case of the ${ }_{6} \Phi_{5}$ summation in (1.6), as well as Watson's [13] $q$-analog of Whipple's theorem.

TheOREM 2.1 (Andrews). For $k \geqq 1$ and $N$ a nonnegative integer:

$$
\begin{aligned}
& { }_{2 k+4} \Phi_{2 k+3}\left[\begin{array}{l}
a, q \sqrt{a},-q \sqrt{a}, b_{1}, c_{1}, \cdots, b_{k-1}, c_{k-1}, b_{k}, c_{k}, q^{-N} \\
\sqrt{a},-\sqrt{a}, \frac{a q}{b_{1}}, \frac{a q}{c_{1}}, \cdots, \frac{a q}{b_{k-1}}, \frac{a q}{c_{k-1}}, \frac{a q}{b_{k}}, \frac{a q}{c_{k}}, a q^{N+1} ; q, \frac{a^{k} q^{k+N}}{b_{1} \cdots b_{k} c_{1} \cdots c_{k}}
\end{array}\right] \\
& =\frac{(a q)_{N}\left(a q / b_{k} c_{k}\right)_{N}}{\left(a q / b_{k}\right)_{N}\left(a q / c_{k}\right)_{N}} \sum_{m_{1}, \ldots, m_{k-1} \geq 0} \frac{\left(a q / b_{1} c_{1}\right)_{m_{1}} \cdots\left(a q / b_{k-1} c_{k-1}\right)_{m_{k-1}}}{(q)_{m_{1}}(q)_{m_{2}} \cdots(q)_{m_{k-1}}} \\
& \times \frac{\left(b_{2}\right)_{m_{1}}\left(c_{2}\right)_{m_{1}}\left(b_{3}\right)_{m_{1}+m_{2}}\left(c_{3}\right)_{m_{1}+m_{2}}}{\left(a q / b_{1}\right)_{m_{1}}\left(a q / c_{1}\right)_{m_{1}}\left(a q / b_{2}\right)_{m_{1}+m_{2}}\left(a q / c_{2}\right)_{m_{1}+m_{2}}} \cdots \frac{\left(b_{k}\right)_{m_{1}+\cdots+m_{k-1}}}{\left(a q / b_{k-1}\right)_{m_{1}+\cdots+m_{k-1}}} \\
& \times \frac{\left(c_{k}\right)_{m_{1}+\cdots+m_{k-1}}}{\left(a q / c_{k-1}\right)_{m_{1}+\cdots+m_{k-1}}} \cdot \frac{\left(q^{-N}\right)_{m_{1}+\cdots+m_{k-1}}}{\left(b_{k} c_{k} q^{-N} / a\right)_{m_{1}+\cdots+m_{k-1}}}
\end{aligned}
$$




$$
\times\left(\frac{a q}{b_{2} c_{2}}\right)^{m_{1}}\left(\frac{a q}{b_{3} c_{3}}\right)^{m_{1}+m_{2}} \cdots\left(\frac{a q}{b_{k-1} c_{k-1}}\right)^{m_{1}+\cdots+m_{k-2}} \cdot q^{m_{1}+m_{2} \cdots+m_{k-1}} .
$$

Observe that if we set $e=q^{-N}$ in (1.14) then,

$$
\frac{(a q)_{N}\left(a q / b_{k} c_{k}\right)_{N}}{\left(a q / b_{k}\right)_{N}\left(a q / c_{k}\right)_{N}}=\Pi\left[\begin{array}{c}
a q, \frac{a q}{c_{k} e}, \frac{a q}{b_{k} e}, \frac{a q}{b_{k} c_{k}} \\
\frac{a q}{b_{k}}, \frac{a q}{c_{k}}, \frac{a q}{e}, \frac{a q}{b_{k} c_{k} e}
\end{array}\right] .
$$

Noting (2.3) it is not hard to see that both sides of (2.2) are analytic functions of $z=1 / e$ in a disk of positive radius about the origin provided that

$$
\frac{a q}{b_{i} c_{i}}=q^{-N_{i}}, \quad 1 \leqq i \leqq k-1
$$

Condition (2.4) terminates the sum on the right hand side of (2.2) but not the sum of the left. If the right hand sum did not terminate then 0 would not be an interior point of the domain of analyticity of the above two functions.

The analytic functions representing both sides of (2.2) are equal when $z=q^{N}, N=1,2, \cdots$ Hence, since 0 is an interior point of the domain of analyticity, both sides of (2.2) are equal when $q^{-N}$ is replaced by the parameter $e$. That is, we have the following extension of Theorem 2.1 in which the left hand side converges, but does not terminate, and the sum on the right hand side terminates:

THEOREM 2.5. For $k \geqq 1$ and

$$
a q / b_{i} c_{i}=q^{-N_{i}}, \quad 1 \leqq i \leqq k-1,
$$

$N_{i}$ a positive integer,

$$
\begin{aligned}
& { }_{2 k+4} \Phi_{2 k+3}\left[\begin{array}{l}
a, q \sqrt{a},-q \sqrt{a}, b_{1}, c_{1}, \cdots, b_{k}, c_{k}, e \\
\left.\sqrt{a},-\sqrt{a}, \frac{a q}{b_{1}}, \frac{a q}{c_{1}}, \cdots, \frac{a q}{b_{k}}, \frac{a q}{c_{k}}, \frac{a q}{e} ; q, \frac{a^{k} q^{k}}{b_{1} \cdots b_{k} c_{1} \cdots c_{k} e}\right]
\end{array}\right] \\
& =\Pi\left[\begin{array}{l}
a q, \frac{a q}{c_{k} e}, \frac{a q}{b_{k} e}, \frac{a q}{b_{k} c_{k}} \\
\frac{a q}{b_{k}}, \frac{a q}{c_{k}}, \frac{a q}{e}, \frac{a q}{b_{k} c_{k} e}
\end{array}\right] \\
& \times \sum_{m_{1}, \cdots, m_{k-1} \geqq 0} \frac{\left(a q / b_{1} c_{1}\right)_{m_{1}}\left(a q / b_{2} c_{2}\right)_{m_{2}} \cdots\left(a q / b_{k-1} c_{k-1}\right)_{m_{k-1}}}{(q)_{m_{1}}(q)_{m_{2}} \cdots(q)_{m_{k-1}}} \\
& \times \frac{\left(b_{2}\right)_{m_{1}}\left(c_{2}\right)_{m_{1}}\left(b_{3}\right)_{m_{1}+m_{2}}\left(c_{3}\right)_{m_{1}+m_{2}} \cdots\left(b_{k}\right)_{m_{1}+\cdots+m_{k-1}}}{\left(a q / b_{1}\right)_{m_{1}}\left(a q / c_{1}\right)_{m_{1}}\left(a q / b_{2}\right)_{m_{1}+m_{2}}\left(a q / c_{2}\right)_{m_{1}+m_{2}} \cdots\left(a q / b_{k-1}\right)_{m_{1}+\cdots+m_{k-}}}
\end{aligned}
$$




$$
\begin{aligned}
& \times \frac{\left(c_{k}\right)_{m_{1}+\cdots+m_{k-1}}}{\left(a q / c_{k-1}\right)_{m_{1}+\cdots+m_{k-1}}} \cdot \frac{(e)_{m_{1}+\cdots+m_{k-1}}}{\left(b_{k} c_{k} e / a\right)_{m_{1}+\cdots+m_{k-1}}} \\
& \times\left(\frac{a q}{b_{2} c_{2}}\right)^{m_{1}}\left(\frac{a q}{b_{3} c_{3}}\right)^{m_{1}+m_{2}} \cdots\left(\frac{a q}{b_{k-1} c_{k-1}}\right)^{m_{1}+\cdots+m_{k-2}} \cdot q^{m_{1}+\cdots+m_{k-1}} .
\end{aligned}
$$

Making use of Theorem 2.5 and Askey and Ismail's proof of (1.5) we now prove Theorem 1.7.

Just as in the proof of Theorem 2.5 it is not hard to see that both sides of the identity in Theorem 1.7 are analytic functions of $z=a / f$ in a disk of poitive radius about the origin provided that (2.4) holds. To complete the proof of Theorem 1.7 we show that these two analytic functions are equal when $z=q^{m}, m=1,2, \ldots$. This will be accomplished once we show that Theorem 1.7 is true with $f=a q^{-m}$. (The key idea here is the "right" choice of the variable $z$. Earlier attempts at this type of proof of (1.5) were made with the variable $z=a$.)

We are now ready to use Theorem 2.5 to show that Theorem 1.7 is true with $f=a q^{-m}$.

Observing that

$$
\frac{(q \sqrt{a})_{n}(-q \sqrt{a})_{n}}{(\sqrt{a})_{n}(-\sqrt{a})_{n}}=\left(1-a q^{2 n}\right) /(1-a),
$$

we see that the left hand side of (1.8) with $f=a q^{-m}$ is:

$$
\begin{aligned}
= & \sum_{n=-m}^{\infty} \frac{\left(1-a q^{2 n}\right)}{(1-a)} \cdot \frac{\left(b_{1}\right)_{n}}{\left(\frac{a q}{b_{1}}\right)_{n}} \cdot \frac{\left(c_{1}\right)_{n}}{\left(\frac{a q}{c_{1}}\right)_{n}} \cdots \frac{\left(b_{k}\right)_{n}}{\left(\frac{a q}{b_{k}}\right)_{n}} \\
& \times \frac{\left(c_{k}\right)_{n}}{\left(\frac{a q}{c_{k}}\right)_{n}} \cdot \frac{(e)_{n}}{\left(\frac{a q}{e}\right)_{n}} \cdot \frac{\left(a q^{-m}\right)_{n}}{\left(q^{m+1}\right)_{n}}\left(\frac{a^{k} q^{k+m}}{b_{1} \cdots b_{k} c_{1} \cdots c_{k} e}\right)^{n} \\
= & \sum_{n=0}^{\infty} \frac{\left(1-a q^{2 n-2 m}\right)}{(1-a)} \cdot \frac{\left(b_{1}\right)_{n-m}}{\left(\frac{a q}{b_{1}}\right)_{n-m}} \cdot \frac{\left(c_{1}\right)_{n-m}}{\left(\frac{a q}{c_{1}}\right)_{n-m}} \cdots \frac{\left(b_{k}\right)_{n-m}}{\left(\frac{a q}{b_{k}}\right)_{n-m}} \cdot \frac{\left(c_{k}\right)_{n-m}}{\left(\frac{a q}{c_{k}}\right)_{n-m}} \\
(2.8) \quad & \times \frac{(e)_{n-m}}{\left(\frac{a q}{e}\right)_{n-m}} \cdot \frac{\left(a q^{-m}\right)_{n-m}}{\left(q^{m+1}\right)_{n-m}}\left(\frac{a^{k} q^{k+m}}{b_{1} \cdots b_{k} c_{1} \cdots c_{k} e}\right)^{n-m} \cdot
\end{aligned}
$$

Note that (1.2) and (1.3) imply that

$$
(a ; q)_{n-m}=(a q)_{-m}\left(a q^{-m} ; q\right)_{n} .
$$

For example,

$$
\left(a q^{-m}\right)_{n-m}=\left(a q^{-m}\right)_{-m}\left(a q^{-2 m}\right)_{n}
$$


and

$$
\left(q^{m+1}\right)_{n-m}=\left(q^{m+1}\right)_{-m}(q ; q)_{n} .
$$

Using (2.9), (2.10), and (2.11) we rewrite (2.8) as:

$$
\frac{\left(b_{1}\right)_{-m}}{\left(\frac{a q}{b_{1}}\right)_{-m}} \cdot \frac{\left(c_{1}\right)_{-m}}{\left(\frac{a q}{c_{1}}\right)_{-m}} \cdots \frac{\left(b_{k}\right)_{-m}}{\left(\frac{a q}{b_{k}}\right)_{-m}} \cdot \frac{\left(c_{k}\right)_{-m}}{\left(\frac{a q}{c_{k}}\right)_{-m}} \cdot \frac{(e)_{-m}}{\left(\frac{a q}{e}\right)_{-m}} \cdot \frac{\left(a q^{-m}\right)_{-m}}{\left(q^{m+1}\right)_{-m}}
$$

$$
\begin{aligned}
& \times \frac{\left(1-a q^{-2 m}\right)}{(1-a)}\left(\frac{b_{1} \cdots b_{k} c_{1} \cdots c_{k} e}{a^{k} q^{k+m}}\right)^{m} \\
& \times \sum_{n=0}^{\infty} \frac{\left(1-a q^{-2 m} q^{2 n}\right)}{\left(1-a q^{-2 m}\right)} \cdot \frac{\left(b_{1} / q^{m}\right)_{n}}{\left(\frac{a q}{b_{1} q^{m}}\right)_{n}} \cdot \frac{\left(c_{1} / q^{m}\right)_{n}}{\left(\frac{a q}{c_{1} q^{m}}\right)_{n}} \cdots \frac{\left(b_{k} / q^{m}\right)_{n}}{\left(\frac{a q}{b_{k} q^{m}}\right)_{n}} \cdot \frac{\left(c_{k} / q_{m}\right)_{n}}{\left(\frac{a q}{c_{k} q^{m}}\right)_{n}} \\
& \times \frac{\left(e / q^{m}\right)_{n}}{\left(\frac{a q}{e q^{m}}\right)_{n}} \cdot \frac{\left(a q^{-2 m}\right)_{n}}{(q)_{n}}\left(\frac{a^{k} q^{k+m}}{b_{1} \cdots b_{k} c_{1} \cdots c_{k} c}\right)^{n} .
\end{aligned}
$$

Note that the sum in (2.13) is the sum on the left hand side of (2.6) with a replaced by $a q^{-2 m}, b_{i}$ by $b_{i} q^{-m}, c_{i}$ by $c_{i} q^{-m}$, and $e$ by $e q^{-m}$. In addition we have,

$$
\frac{a q^{-2 m} q}{b_{i} q^{-m} c_{i} q^{-m}}=\frac{a q}{b_{i} c_{i}} \cdot \frac{q^{-2 m}}{q^{-2 m}}=\frac{a q}{b_{i} c_{i}}=q^{-N_{i}} .
$$

Thus we can replace the sum in (2.13) by the right hand side of (2.6) with a replaced by $a q^{-2 m}, b_{i}$ by $b_{i} q^{-m}, c_{i}$ by $c_{i} q^{-m}$, and $e$ by $e q^{-m}$. When this is done the product of the products in (2.12) and the sum in (2.13) become:

$$
\frac{\left(b_{1}\right)_{-m}}{\left(\frac{a q}{b_{1}}\right)_{-m}} \cdot \frac{\left(c_{1}\right)_{-m}}{\left(\frac{a q}{c_{1}}\right)_{-m}} \cdots \frac{\left(b_{k}\right)_{-m}}{\left(\frac{a q}{b_{k}}\right)_{-m}} \cdot \frac{\left(c_{k}\right)_{-m}}{\left(\frac{a q}{c_{k}}\right)_{-m}} \cdot \frac{(e)_{-m}}{\left(\frac{a q}{e}\right)_{-m}} \cdot \frac{\left(a q^{-m}\right)_{-m}}{\left(q^{m+1}\right)_{-m}}
$$

$$
\begin{aligned}
& \times\left(\frac{b_{1} \cdots b_{k} c_{1} \cdots c_{k} e}{a^{k} q^{k+m}}\right)^{m} \\
& \times \frac{\left(1-a q^{-2 m}\right)}{(1-a)}\left(a q / q^{2 m}\right)_{\infty} \\
& \times\left(\frac{a q}{c_{k} e}\right)_{\infty}\left(\frac{a q}{b_{k} e}\right)_{\infty}\left(\frac{a q}{b_{k} c_{k}}\right)_{\infty} /\left(\frac{a q q^{m}}{b_{k} c_{k} e}\right)_{\infty} \\
& \times\left(\frac{a q}{b_{k} q^{m}}\right)_{\infty}^{-1}\left(\frac{a q}{c_{k} q^{m}}\right)_{\infty}^{-1}\left(\frac{a q}{e q^{m}}\right)_{\infty}^{-1}
\end{aligned}
$$$$
\times \sum_{m_{1}, \cdots, m_{k-1} \geqq 0} \frac{\left(a q / b_{1} c_{1}\right)_{m_{1}}\left(a q / b_{2} c_{2}\right)_{m_{2}} \cdots\left(a q / b_{k-1} c_{k-1}\right)_{m_{k-1}}}{(q)_{m_{1}}(q)_{m_{2}} \cdots(q)_{m_{k-1}}}
$$ 
426

STEPHEN C. MILNE

$$
\begin{aligned}
& \times \frac{\left(b_{2} / q^{m}\right)_{m_{1}}}{\left(a q / b_{1} q^{m}\right)_{m_{1}}} \cdot \frac{\left(c_{2} / q^{m}\right)_{m_{1}}}{\left(a q / c_{1} q^{m}\right)_{m_{1}}} \cdot \frac{\left(b_{3} / q^{m}\right)_{m_{1}+m_{2}}}{\left(a q / b_{2} q^{m}\right)_{m_{1}+m_{2}}} \cdot \frac{\left(c_{3} / q^{m}\right)_{m_{1}+m_{2}}}{\left(a q / c_{2} q^{m}\right)_{m_{1}+m_{2}}} \\
& \cdots \frac{\left(b_{k} / q^{m}\right)_{m_{1}+\cdots+m_{k-1}}}{\left(a q / b_{k-1} q^{m}\right)_{m_{1}+\cdots+m_{k-1}}} \cdot \frac{\left(c_{k} / q^{m}\right)_{m_{1}+\cdots+m_{k-1}}}{\left(a q / c_{k-1} q^{m}\right)_{m_{1}+\cdots+m_{k-1}}} \\
& \times \frac{\left(e / q^{m}\right)_{m_{1}+\cdots+m_{k-1}}}{\left(b_{k} c_{k} e / a q^{m}\right)_{m_{1}+\cdots+m_{k-1}}} \cdot q^{m_{1}+\cdots+m_{k-1}} \\
& \times\left(\frac{a q}{b_{2} c_{2}}\right)^{m_{1}} \cdot\left(\frac{a q}{b_{3} c_{3}}\right)^{m_{1}+m_{2}} \cdots\left(\frac{a q}{b_{k-1} c_{k-1}}\right)^{m_{1}+\cdots+m_{k-2}}
\end{aligned}
$$

It is not hard to see that the sum in (2.19) is the sum in (1.11) with $f=a q^{-m}$. All that is left in the proof of Theorem 1.7 is to show that the product of the terms in (2.14) through (2.18) is nothing but the products in (1.8), (1.9), and (1.10) with $f=a q^{-m}$.

When the products in (2.14) are simplified using (1.3) and then combined with (2.15) we obtain:

$$
\frac{\left(b_{1} / a\right)_{m}\left(b_{2} / a\right)_{m} \cdots\left(b_{k-1} / a\right)_{m}}{\left(q / c_{1}\right)_{m}\left(q / c_{2}\right)_{m} \cdots\left(q / c_{k-1}\right)_{m}}
$$

$$
\begin{aligned}
& \times \frac{\left(c_{1} / a\right)_{m}\left(c_{2} / a\right)_{m} \cdots\left(c_{k-1} / a\right)_{m}}{\left(q / b_{1}\right)_{m}\left(q / b_{2}\right)_{m} \cdots\left(q / b_{k-1}\right)_{m}} \cdot \frac{1}{\left(b_{1} \cdots b_{k-1}\right)^{m}} \cdot \frac{1}{\left(c_{1} \cdots c_{k-1}\right)^{m}} \\
& \times \frac{\left(b_{k} / a\right)_{m}\left(c_{k} / a\right)_{m}(e / a)_{m} a^{m k} q^{m^{2}+(k+2) m}}{\left(b_{k} c_{k} e\right)^{m}} \\
& \times\left(q^{m+1} / a\right)_{m}^{-1}=(-1)^{m} a^{m} q^{-1 / 2 m(3 m+1)} \cdot\left(1-\frac{a}{q^{2 m}}\right)^{-1} \cdots\left(1-\frac{a}{q^{m+1}}\right)^{-1} \\
& \times\left(1 / q^{m}\right)_{m}=(-1)^{m} q^{-1 / 2 m(m+1)} \\
& \times(q)_{m} \\
& \times\left(q / b_{k}\right)_{m}^{-1}\left(q / c_{k}\right)_{m}^{-1}(q / e)_{m}^{-1} .
\end{aligned}
$$

Observe that

$$
b_{i}^{m}\left(q / b_{i}\right)_{m}=(-1)^{m} q^{1 / 2 m(m+1)} \cdot\left(b_{i} / q^{m}\right)_{m}
$$

and

$$
c_{i}^{-m}\left(c_{i} / a\right)_{m}=(-1)^{m} a^{-m} q^{1 / 2 m(m-1)} \cdot\left(a q / c_{i} q^{m}\right)_{m} .
$$

Thus (2.21) can be rewritten as:

$$
\begin{aligned}
& \frac{\left(a q / c_{1} q^{m}\right)_{m} \cdots\left(a q / c_{k-1} q^{m}\right)_{m}}{\left(b_{1} / q^{m}\right)_{m} \cdots\left(b_{k-1} / q^{m}\right)_{m}} \\
& \times(a q)^{-(k-1) m} .
\end{aligned}
$$


After some algebraic simplification we find that (2.16) can be rewritten as

$$
\begin{aligned}
& (a q)_{\infty}(q / a)_{m} \\
& \quad \times(-1)^{m} a^{m} q^{-1 / 2 m(m+1)} \cdot\left(1-\frac{a}{q^{2 m}}\right) \cdots\left(1-\frac{a}{q^{m+1}}\right),
\end{aligned}
$$

and that (2.18) can be rewritten as

$$
\begin{aligned}
& \left(a q / b_{k}\right)_{\infty}^{-1}\left(a q / c_{k}\right)_{\infty}^{-1}(a q / e)_{\infty}^{-1} \\
& \quad \times \frac{(-1)^{m}(a q)^{-3 m} q^{3 / 2 m(m+1)}\left(b_{k} c_{k} e\right)^{m}}{\left(b_{k} / a\right)_{m}\left(c_{k} / a\right)_{m}(e / a)_{m}} .
\end{aligned}
$$

The product of the terms in (2.17), (2.25), (2.26), (2.29) and (2.31) is:

$$
\begin{aligned}
& \frac{(a q)_{\infty}\left(a q / c_{k} e\right)_{\infty}\left(a q / b_{k} e\right)_{\infty}\left(a q / b_{k} c_{k}\right)_{\infty}}{\left(a q / b_{k}\right)_{\infty}\left(a q / c_{k}\right)_{\infty}(a q / e)_{\infty}\left(a q \cdot q^{m} / b_{k} c_{k} e\right)_{\infty}} \\
& \quad \times \frac{(q / a)_{m}(q)_{m}}{\left(q / b_{k}\right)_{m}\left(q / c_{k}\right)_{m}(q / e)_{m}} .
\end{aligned}
$$

The product of the terms in (2.20) and (2.7) is:

$$
\frac{\left\{\left(b_{1} / a\right)_{m} \cdots\left(b_{k-1} / a\right)_{m}\right\} \cdot\left\{\left(a q / c_{1} q^{m}\right)_{m} \cdots\left(a q / c_{k-1} q^{m}\right)_{m}\right\}}{\left\{\left(b_{1} / q^{m}\right)_{m} \cdots\left(b_{k-1} / q^{m}\right)_{m}\right\} \cdot\left\{\left(q / c_{1}\right)_{m} \cdots\left(q / c_{k-1}\right)_{m}\right\}} .
$$

A routine algebraic simplification shows that the product of the terms in (2.22), (2.32), (2.23), (2.30), (2.24), and (2.28) is 1 .

Using (1.2) to rewrite the products in (2.34) it is not hard to see that the product of terms in $(2.33)$ and $(2.34)$ is simply $(1,8)$ with $f=a q^{-m}$.

Similarly, (1.2) implies that (2.35) is the product of (1.9) and (1.10) with $f=a q^{-m}$.

This completes the proof of Theorem 1.7.

3. Applications. As an application of Theorem 1.7 we give a new proof of the following partition identity due to Andrews [3, $\S 6]$.

TheOREM 3.1 (Andrews).

$$
\begin{aligned}
& \frac{1}{\left(\alpha_{1}\right)_{\infty}\left(\alpha_{2}\right)_{\infty} \cdots\left(\alpha_{k-1}\right)_{\infty}} \\
& =\sum_{m_{1}, \cdots, m_{k-1} \geqq 0} \frac{q^{\sigma_{1}\left(m_{1}, \cdots, m_{k-1}\right)^{2}-\sigma_{2}\left(m_{1}, \cdots, m_{k-1}\right)-\sigma_{1}\left(m_{1}, \cdots, m_{k-1}\right)}}{(q)_{m_{1}}(q)_{m_{2}} \cdots(q)_{m_{k-1}}}
\end{aligned}
$$




$$
\times \frac{\alpha_{1}^{m_{1}} \alpha_{2}^{m_{2}} \cdots \alpha_{k-1}^{m_{k}-1}}{\left(\alpha_{1}\right)_{m_{1}}\left(\alpha_{2}\right)_{m_{1}+m_{2}} \cdots\left(\alpha_{k-1}\right)_{m_{1}+\cdots+m_{k-1}}},
$$

where $\sigma_{i}\left(m_{1}, \cdots, m_{k-1}\right)$ is the ith elementary symmetric function of the $m_{1}, \cdots, m_{k-1}$.

Recalling MacMahon's formula for $\pi_{k}(m)$ the number of plane partitions of $m$ with $k$ rows [10; p. 243], Andrews [3, §6] has observed that if $\alpha_{i}$ is replaced by $q^{i}$ in (3.2) then,

$$
\sum_{m=0}^{\infty} \pi_{k}(m) q^{m}=\sum_{m_{1}, \cdots, m_{k} \geqq 0} \frac{q^{\sigma_{1}\left(m_{1}, \cdots, m_{k}\right)^{2}-\sigma_{2}\left(m_{1}, \cdots, m_{k}\right)+m_{2}+2 m_{3}+\cdots+(k-1) m_{k}}}{(q)_{m_{1}} \cdots(q)_{m_{k}}(q)_{m_{1}}\left(q^{2}\right)_{m_{1}+m_{2}} \cdots\left(q^{k}\right)_{m_{1}+\cdots+m_{k}}} .
$$

In order to prove (3.2) we choose the parameters in Theorem 1.7 as follows:

$$
\begin{aligned}
& b_{i}=\alpha_{i} q^{2 N} \\
& c_{i}=a q / \alpha_{i} q^{N} \\
& f=a q^{-N} \\
& b_{l k}, c_{k}, e \text { are nonzero constants independent of } N .
\end{aligned}
$$

This choice of parameters satisfies the terminating condition in (1.12) since $a q / b_{i} c_{i}=q^{-N}$.

Observe that

$$
\lim _{N \rightarrow \infty} b_{i}=0 \text { and } \lim _{N \rightarrow \infty} c_{i}=\infty
$$

since $|q|<1$.

Now $b_{i}$ and $c_{i}$ contribute

$$
\begin{aligned}
& \frac{\left(b_{i}\right)_{n}\left(c_{i}\right)_{n}}{\left(a q / b_{i}\right)_{n}\left(a q / c_{i}\right)_{n}} \cdot \frac{1}{\left(b_{i} c_{i}\right)^{n}} \\
& \quad=\frac{1}{(a q)^{n}} \cdot \frac{\left(b_{i}\right)_{n}}{\left(a q / c_{i}\right)_{n}} \cdot \frac{\left(1-1 / c_{i}\right) \cdots\left(q^{n-1}-1 / c_{i}\right)}{\left(1-b_{i} / a q\right) \cdots\left(q^{n-1}-b_{i} / a q\right)}
\end{aligned}
$$

to the sum on the left hand side of (1.8).

If we fix $n$ and let $N \rightarrow \infty$ then (3.4) implies that (3.5) tends to

$$
\frac{1}{(a q)^{n}} \cdot \frac{q_{2}^{(n)}}{q_{2}^{(n)}}=\frac{1}{(a q)^{n}} \text {. }
$$

An appeal to Tannery's Theorem [7; 49] immediately implies that the sum on the left hand side of (1.8) converges to:

$$
\begin{aligned}
& { }_{6} \Psi_{6}\left[\begin{array}{l}
q \sqrt{a},-q \sqrt{a}, b_{k}, c_{k}, e, f \\
\sqrt{a},-\sqrt{a}, a q / b_{k}, a q / c_{k}, a q / e, a q / f
\end{array} ; q ; \frac{a^{k+1} q^{k}}{(a q)^{k-1} \cdot b_{k} c_{k} e f}\right] \\
& ={ }_{6} \Psi_{6}\left[\begin{array}{l}
q \sqrt{a},-q \sqrt{a}, b_{k}, c_{k}, e, f \\
\sqrt{a},-\sqrt{a}, a q / b_{k}, a q / c_{k}, a q / e, a q / f
\end{array} ; q ; \frac{a^{2} q}{b_{b_{k}} c_{k} e f}\right]
\end{aligned}
$$




$$
=\Pi\left[\begin{array}{c}
a q, \frac{a q}{b_{k} c_{k}}, \frac{a q}{b_{k} e}, \frac{a q}{b_{k} f}, \frac{a q}{c_{k} e}, \frac{a q}{c_{k} f}, \frac{a q}{e f}, q, \frac{q}{a} \\
\frac{q}{b_{k}}, \frac{q}{c_{k}}, \frac{q}{e}, \frac{q}{f}, \frac{a q}{b_{k}}, \frac{a q}{c_{k}}, \frac{a q}{e}, \frac{a q}{f}, \frac{a^{2} q}{b_{k} c_{k} e f}
\end{array}\right],
$$

by Bailey's ${ }_{6} \Psi_{6}$ summation in (1.5).

Note that the products in (3.7) are exactly the same as those in (1.8), and thus may be cancelled from both sides on (1.8).

When the parameters in (3.3) are used and we let $N \rightarrow \infty$, an application of Tannery's Theorem for products $[7 ; \S 49]$ implies that the products in (1.9) and (1.10) become:

$$
\left(\alpha_{1}\right)_{\infty}\left(\alpha_{2}\right)_{\infty} \cdots\left(\alpha_{k-1}\right)_{\infty} \text {. }
$$

When the parameters in (3.3) are substituted into the sum in (1.11) we obtain:

$$
\begin{aligned}
& \sum_{m_{1}, \cdots, m_{k-1} \geqq 0} \frac{\left(q^{-N}\right)_{m_{1}}\left(q^{-N}\right)_{m_{2}} \cdots\left(q^{-N}\right)_{m_{k-1}} \cdot q^{m_{1}+\cdots+m_{k-1}}}{(q)_{m_{1}}(q)_{m_{2}} \cdots(q)_{m_{k-1}}\left(\alpha_{1}\right)_{m_{1}}\left(\alpha_{2}\right)_{m_{1}+m_{2}} \cdots\left(\alpha_{k-1}\right)_{m_{1}+\cdots+m_{k-1}}} \\
& \quad \times \frac{\left(b_{k} q^{-N}\right)_{m_{1}+\cdots+m_{k-1}}\left(c_{k} q^{-N}\right)_{m_{1}+\cdots+m_{k-1}}\left(e q^{-N}\right)_{m_{1}+\cdots+m_{k-1}}}{\left(a q^{1-3 N} / \alpha_{k-1}\right)_{m_{1}+\cdots+m_{k-1}}\left(b_{k} c_{k} e q^{-N} / a\right)_{m_{1}+\cdots+m_{k-1}}} \\
& \quad \times \frac{\left(a q^{1-2 N} / \alpha_{2}\right)_{m_{1}}\left(a q^{1-2 N} / \alpha_{3}\right)_{m_{1}+m_{2}} \cdots\left(a q^{1-2 N} / \alpha_{k-1}\right)_{m_{1}+\cdots+m_{k-2}}}{\left(a q^{1-3 N} / \alpha_{1}\right)_{m_{1}}\left(a q^{1-3 N} / \alpha_{2}\right)_{m_{1}+m_{2}} \cdots\left(a q^{1-3 N} / \alpha_{k-2}\right)_{m_{1}+\cdots+m_{k-2}}} \\
& \quad \times\left(q^{-N}\right)^{m_{1}+\left(m_{1}+m_{2}\right)+\cdots+\left(m_{1}+\cdots+m_{k-2}\right)} \\
& \quad \times\left(\alpha_{2} q^{N}\right)_{m_{1}}\left(\alpha_{3} q^{N}\right)_{m_{1}+m_{2}} \cdots\left(\alpha_{k-1} q^{N}\right)_{m_{1}+\cdots+m_{k-2}} .
\end{aligned}
$$

By making use of the relation

$$
(a ; q)_{m}=(-1)^{m} a^{m}\left(1-\frac{1}{a}\right)\left(q-\frac{1}{a}\right) \cdots\left(q^{m-1}-\frac{1}{a}\right)
$$

to rewrite the products involving $q^{-N}$, we find after some algebraic simplification that when $N \rightarrow \infty$ the general term of the sum in (3.9) becomes:

$$
\begin{aligned}
& \frac{q^{\sigma_{1}\left(m_{1}, \cdots, m_{k-1}\right)^{2}-\sigma_{2}\left(m_{1}, \cdots, m_{k-1}\right)-\sigma_{1}\left(m_{1}, \cdots, m_{l-1}\right)}}{(q)_{m_{1}}(q)_{m_{2}} \cdots(q)_{m_{k-1}}} \\
& \quad \times \frac{\alpha_{1}^{m_{1}} \alpha_{2}^{m_{2}} \cdots \alpha_{k-1}^{m_{k-1}}}{\left(\alpha_{1}\right)_{m_{1}}\left(\alpha_{2}\right)_{m_{1}+m_{2}} \cdots\left(\alpha_{k-1}\right)_{m_{1}+\cdots+m_{k-1}}} .
\end{aligned}
$$

An application of Tannery's Theorem now implies that when $N \rightarrow \infty$, the sum in (3.9) converges to the sum in (3.2).

Putting everything together we find that 1 equals the products in (3.8) times the sum in (3.2). This finishes the proof of Theorem 3.1 . 
Note that we have obtained Theorem 3.1 as a limiting case of Theorem 1.7.

\section{REFERENCES}

1. G. E. Andrews, Applications of basic hypergeometric functions, SIAM Review, 16 (1974), 441-484.

2. - Problems and prospects for basic hypergeometric functions, The Theory and Applications of Special Functions (R. Askey, ed.), 191-224. Academic Press, New York, 1975.

3. Connection coefficient problems and partitions, from Proceedings of Symposia in Pure Mathematics, Vol. XXXIV, (D. K. Ray-Chaudhuri, ed) Amer. Math. Soc., Providence, 1979, 1-24.

4. — The Theory of Partitions, Encyclopedia of Mathematics, V. 2, AddisonWesley, Reading, Mass., 1976.

5. R. Askey and M. Ismail, The very well poised ${ }_{6} \Psi_{6}$, to appear in Proc. Amer. Math. Soc.

6. W. N. Bailey, Series of hypergeometric type which are infinite in both directions, Quart. J. Math., 7 (1936), 105-115.

7. T. J. I'A. Bromwich, An Introduction to the Theory of In finite Series, MacMillan and Co., Limited, St. Martin's Street, London, 1949.

8. M. Ismail, A simple proof of Ramanujan's ${ }_{1} \Psi_{1}$ sum, Proc. of the Amer. Math. Soc., 63 (1977), 185-186.

9. M. Jackson, On well-poised bilateral hypergeometric series of the type ${ }_{8} \Psi_{8}$ ' Quart. J. Math. (Oxford) (2), 1 (1950), 63-68.

10. P. A. MacMahon, Combinatory Analysis, Vol. 2, Cambridge University Press, London, 1915 (Reprinted: Chelsea, New York, 1964).

11. L. J. Slater, A new proof of Roger's transformations of infinite series, Proc. London Math. Soc., (2) 53 (1951), 460-475.

12. L. J. Slater and A. Lakin, Two proofs of the ${ }_{8} \Psi_{6}$ summation theorem, Proc. Edinburgh Math. Soc., 9 (1956), 116-121.

13. G. N. Watson, A new proof of the Rogers-Ramanujan identities, J. London Math. Soc., $4(1930)^{`} 4-9$.

Received February 28, 1979. Partially supported by NSF Grant MCS 79-01722.

Texas A \& M University

College Station, TX 77843 


\section{PACIFIC JOURNAL OF MATHEMATICS}

\section{EDITORS}

DONALD BABBITT (Managing Editor)

University of California

Los Angeles, CA 90024

Hugo RossI

University of Utah

Salt Lake City, UT 84112

C. C. MOORE and ANDREW OGG

University of California

Berkeley, CA 94720

\section{J. DugundjI}

Department of Mathematics

University of Southern California

Los Angeles, CA 90007

R. FinN and J. Milgram

Stanford University

Stanford, CA 94305

\section{ASSOCIATE EDITORS}
E. F. BeCKENBACH
B. H. Neumann
F. WoLF
K. YoSHIDA

\section{SUPPORTING INSTITUTIONS}

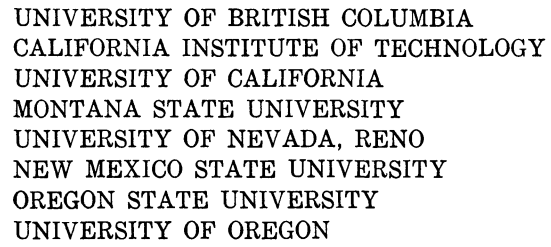

UNIVERSITY OF BRITISH COLUMBIA CALIFORNIA INSTITUTE OF TECHNOLOGY UNIVERSITY OF CALIFORNIA MONTANA STATE UNIVERSITY UNIVERSITY OF NEVADA, RENO NEW MEXICO STATE UNIVERSITY OREGON STATE UNIVERSITY UNIVERSITY OF OREGON

\author{
UNIVERSITY OF SOUTHERN CALIFORNIA \\ STANFORD UNIVERSITY \\ UNIVERSITY OF HAWAII \\ UNIVERSITY OF TOKYO \\ UNIVERSITY OF UTAH \\ WASHINGTON STATE UNIVERSITY \\ UNIVERSITY OF WASHINGTON
}

The Supporting Institutions listed above contribute to the cost of publication of this Journal, but they are not owners or publishers and have no responsibility for its content or policies.

Mathematical papers intended for publication in the Pacific Journal of Mathematics should be in typed form or offset-reproduced, (not dittoed), double spaced with large margins. Please do not use built up fractions in the text of the manuscript. However, you may use them in the displayed equations. Underline Greek letters in red, German in green, and script in blue. The first paragraph or two must be capable of being used separately as a synopsis of the entire paper. Please propose a heading for the odd numbered pages of less than 35 characters. Manuscripts, in triplicate, may be sent to any one of the editors. Please classify according to the scheme of Math. Reviews, Index to Vol. 39. Supply name and address of author to whom proofs should be sent. All other communications should be addressed to the managing editor, or Elaine Barth, University of California, Los Angeles, California, 90024.

50 reprints to each author are provided free for each article, only if page charges have been substantially paid. Additional copies may be obtained at cost in multiples of 50 .

The Pacific Journal of Mathematics is issued monthly as of January 1966. Regular subscription rate: $\$ 84.00$ a year (6 Vols., 12 issues). Special rate: $\$ 42.00$ a year to individual members of supporting institutions.

Subscriptions, orders for numbers issued in the last three calendar years, and changes of address shoud be sent to Pacific Journal of Mathematics, P.O. Box 969, Carmel Valley, CA 93924, U.S.A Old back numbers obtainable from Kraus Periodicals Co., Route 100, Millwood, NY 10546.

PUBLISHED BY PACIFIC JOURNAL OF MATHEMATICS, A NON-PROFIT CORPORATION

Printed at Kokusai Bunken Insatsusha (International Academic Printing Co., Ltd.). 8-8, 3-chome, Takadanobaba, Shinjuku-ku, Tokyo 160, Japan. 


\section{Pacific Journal of Mathematics}

\section{Vol. 91, No. 2 December, 1980}

Victor P. Camillo and Julius Martin Zelmanowitz, Dimension modules ... . . 249

Yonina S. Cooper, Stable sequences in pre-abelian categories ........... 263

Chandrakant Mahadeorao Deo and H. Ship-Fah Wong, On Berry-Esseen approximation and a functional LIL for a class of dependent random fields.........................................

H. P. Dikshit and S. N. Dubey, $|C, 1|$ summability of series associated with

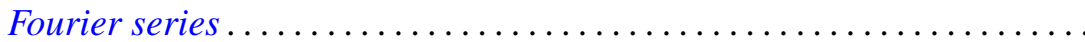

M. Edelstein, On the homomorphic and isomorphic embeddings of a semiflow into a radial flow.

Gilles Godefroy, Compacts de Rosenthal ..................... 293

James Guyker, Commuting hyponormal operators ................ 307

Thomas Eric Hall and Peter R. Jones, On the lattice of varieties of bands of

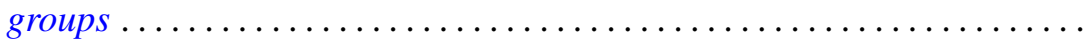

Taqdir Husain and Saleem H. Watson, Topological algebras with orthogonal Schauder bases ....................................

V. K. Jain, Some expansions involving basic hypergeometric functions of two variables. . .

Joe W. Jenkins, On group actions with nonzero fixed points ........... 363

Michael Ellsworth Mays, Groups of square-free order are scarce ........ 373

Michael John McAsey, Canonical models for invariant subspaces... 377

Peter A. McCoy, Singularities of solutions to linear second order elliptic partial differential equations with analytic coefficients by approximation methods...

Terrence Millar, Homogeneous models and decidability.

Stephen Carl Milne, A multiple series transformation of the very well poised

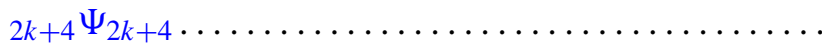

Robert Olin and James E. Thomson, Irreducible operators whose spectra are spectral sets...

Robert John Piacenza, Cohomology of diagrams and equivariant singular

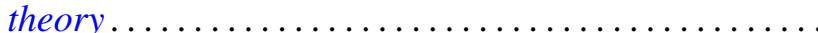

Louis Jackson Ratliff, Jr., Integrally closed ideals and asymptotic prime divisors

Robert Breckenridge Warfield, Jr., Cancellation of modules and groups and stable range of endomorphism rings.................

B. J. Day, Correction to: "Locale geometry" ...............

Stanley Stephen Page, Correction to: "Regular FPF rings" ... 